\title{
More is more in language learning: reconsidering the less-is-more hypothesis
}

Patricia J. Brooks

Vera Kempe

This is the peer reviewed version of the following article: Brooks, P.J. and Kempe, V. (2018) 'More is more in language learning: reconsidering the less-ismore hypothesis', Language Learning, which has been published in final form at https://dx.doi.org/

10.1111/lang.12320. This article may be used for noncommercial purposes in accordance with Wiley Terms and Conditions for Self-Archiving." 
Running Head: Reconsidering the Less-is-More Hypothesis

More is More in Language Learning:

Reconsidering the Less-is-More Hypothesis

\author{
Patricia J. Brooks \\ College of Staten Island and the Graduate Center, CUNY \\ Vera Kempe \\ Abertay University
}

Address correspondence to:

Patricia J. Brooks

Department of Psychology

College of Staten Island, CUNY

2800 Victory Blvd., 4S-108

Staten Island, NY 10314

patricia.brooks@csi.cuny.edu 
RECONSIDERING THE LESS-IS-MORE HYPOTHESIS 2

\begin{abstract}
The Less-is-More hypothesis was proposed to explain age-of-acquisition effects in first language (L1) acquisition and second language (L2) attainment. We scrutinize different renditions of the hypothesis by examining how learning outcomes are affected by (1) limited cognitive capacity, (2) reduced interference resulting from less prior knowledge, and (3) simplified language input. While there is little-to-no evidence of benefits of limited cognitive capacity, there is ample support for a More-is-More account linking enhanced capacity with better L1- and L2-learning outcomes, and reduced capacity with childhood language disorders. Instead, reduced prior knowledge (relative to adults) may afford children with greater flexibility in inductive inference; this contradicts the idea that children benefit from a more constrained hypothesis space. Finally, studies of childdirected speech (CDS) confirm benefits from less complex input at early stages, but also emphasize how greater lexical and syntactic complexity of the input confers benefits in L1attainment.
\end{abstract}

Keywords: less is more; more is more; working memory; cognitive control; processing capacity; individual differences 
RECONSIDERING THE LESS-IS-MORE HYPOTHESIS 3

\section{More is More in Language Learning: Reconsidering the Less-is-More Hypothesis}

There is broad agreement that to acquire language, suitable input needs to be available early in development. In this review, we consider whether children's limited cognitive capacity can provide a viable explanation for such critical period effects. We conclude that direct evidence that less cognitive capacity supports language learning is lacking. Instead, we argue that with respect to many aspects of cognitive functioning more capacity is beneficial for L2- as well as for L1-learning and that the Less-is-More hypothesis might be more appropriately applied to children's limited prior knowledge and the reduced complexity of the input typically provided to them, which may explain children's superior outcomes in some (but not all) language learning contexts.

Aside from a few case studies (e.g., Curtiss, 1977), direct evidence for the duration of a critical period for L1-acquisition is difficult to obtain, simply because it is impossible to compare sufficient numbers of individuals with early vs. late onset of oral L1acquisition. Given this limitation, evidence for a critical period relies on two sources of evidence. The first set of findings comes from congenitally deaf individuals deprived of early language input due to lack of access to a sign language and/or societal insistence on oral communication (e.g., Grimshaw, Adelstein, Bryden, \& MacKinnon, 1998; Mayberry, Lock, \& Kazmi, 2002). Compared to native signers (i.e., hearing or deaf individuals exposed to sign from birth, typically by deaf parents), late signers (i.e., deaf individuals exposed to sign language at school age or later) demonstrate measurable deficits in the quality of their signing over the lifespan: They exhibit difficulties acquiring the complex morphological and grammatical constructions of American Sign Language (ASL), are less 


\section{RECONSIDERING THE LESS-IS-MORE HYPOTHESIS 4}

sensitive to grammatical errors (Emmorey, Bellugi, Friederici, \& Horn 1995; Newport, 1998; Mayberry \& Eichen, 1991), and are also at a disadvantage in acquiring an oral language as an L2 for literacy purposes (Mayberry, 2007; Mayberry \& Lock, 2003). Such age-of-acquisition effects are corroborated by studies of congenitally deaf recipients of cochlear implants who fare markedly better when implantation is done at a young age (Connor, Craig, Raudenbush, Heavner, \& Zwolan, 2006; Robbins, Koch, Osberger, Zimmerman-Phillips, \& Kishon-Rabin, 2004). These findings suggest that for deaf individuals denied useable language input in early childhood, the window of opportunity for acquiring the full complexity of a natural language may well be closed, presumably because the neurophysiological processes involved in establishing pathways for language processing are redirected towards other tasks (Cheng, Halgren, \& Mayberry, 2018; Newman, Bavelier, Corina, Jezzard, \& Neville, 2002).

The second set of findings that is often taken as support of a critical period for language learning comes from the domain of L2-learning, where later age of first L2exposure has been linked to deficits in ultimate L2-attainment, summarized by the perhaps too general claim that children are better L2-learners than adults. For example, an influential study involving native Korean and Chinese learners of English demonstrated that accuracy in judging the grammaticality of a wide range of English constructions declined steadily as a function of learners' age of first L2-exposure up to puberty, even when other experiential and attitudinal variables such as overall years of L2-exposure, amount of classroom instruction, identification with social values of the host country, degree of self-consciousness, and motivation to learn the L2 and to speak it well were taken into account (Johnson \& Newport, 1989). Although these and similar studies have been 


\section{RECONSIDERING THE LESS-IS-MORE HYPOTHESIS 5}

shown to be severely underpowered (Hartshorne, Tenenbaum \& Pinker, 2018; Vanhove, 2013), recent evidence from an extraordinarily large sample exceeding half a million L1and L2-speakers of English confirms that ultimate grammatical proficiency declines with age of first L2-exposure, even if the estimated offset of the critical period between 17 and 18 years appears to be much later than previously estimated (Hartshorne et al., 2018).

Traditionally, differences in ultimate L2-attainment as a function of age of first L2exposure have been attributed to maturational changes that diminish the ability of older learners to acquire an L2 (Lenneberg, 1967; Patkowski, 1990; Pakulak \& Neville, 2011; Weber-Fox \& Neville, 1996). Yet maturational explanations need to be reconciled with evidence that cognitive capacity increases with age (Anderson, 2002; Cowan, 2016; Fry \& Hale, 2000). To account for this paradox, Newport (1990) offered the hypothesis that agerelated increases in cognitive abilities might make language learning more difficult, suggesting that less may be more in language acquisition.

\section{The 'Less-is-More' hypothesis}

At the heart of this hypothesis is the idea that imposing constraints on the capacity to extract information from language input may benefit learning. Although rarely stated explicitly in the language learning literature, this idea is firmly embedded within an evolutionary approach that views cognitive and social immaturity arising from a prolonged juvenile period in humans as a crucial pre-requisite for many aspects of human development (Bjorklund, 2018). With respect to language, researchers have proposed a range of mechanisms linking cognitive constraints to better learning outcomes. Below we briefly describe the various mechanisms that may support the Less-is-More hypothesis before scrutinizing its empirical basis. 


\section{RECONSIDERING THE LESS-IS-MORE HYPOTHESIS 6}

Working memory limitations. Newport $(1990,1998)$ proposed that domain-general capacity limitations might explain why children are more successful at learning languages than adults. Specifically, she suggested that limited working-memory capacity restricts children's attention to fewer and smaller chunks comprising shorter linguistic units, which in turn might facilitate their detecting and analyzing adjacent dependencies and other patterns of linguistic co-variation necessary for acquiring morpho-syntactic rules (Goldowsky \& Newport, 1993; see also Kareev, 1995; Turkewitz \& Kenny, 1982). In contrast, adults with their larger working-memory capacity are likely to store larger linguistic units, thereby overlooking variation in morpho-syntactic features or failing to decompose phrases and words into constituent morphemes (but see Arnon \& Christiansen, 2017). Under this view, young children's inability to process the full complexity of possible linguistic mappings selectively filters the input, consequently serving to restrict children's hypotheses about form-meaning mappings to the most relevant ones.

Executive control limitations. A related account suggests that limitations in cognitive control confer early learning advantages (Chrysikou, Novick, Trueswell, \& Thomspon-Schill, 2011; Thompson-Schill, Ramscar \& Chrysikou, 2009). Reduced executive functioning limits children's ability to inhibit pre-potent responses and make probabilistic predictions, which renders them liable to regularize unpredictable variation by favoring one particular form-function mapping over others. Adults, on the other hand, are more likely to probability-match: Their responses tend to reflect the quantitative distribution of competing form-function mappings in the input. This link between cognitive-control limitations and regularization has been invoked as an explanation for the role of children in creolization processes, wherein the grammar of a pidgin becomes more 


\section{RECONSIDERING THE LESS-IS-MORE HYPOTHESIS 7}

structured over time (Hudson Kam \& Newport, 2005; 2009), e.g. in Nicaraguan Sign Language, where younger cohorts of learners have altered the system by decomposing signs into syntactically motivated spatial morphemes (Senghas \& Coppola, 2001; Senghas, Kita, \& Özyürek, 2004).

Limitations in procedural learning. Another variant of the Less-is-More hypothesis suggests that age-of-acquisition effects on language learning outcomes are linked to a qualitative developmental shift from implicit, procedural learning to more explicit, attention-driven learning (cf. Karmiloff-Smith, 1992; Ullman, 2001; Zwart, Vissers, Kessels, \& Maes, 2017 for models of this trajectory), which may hinder aspects of language learning that involve processing of sequential information. In line with this view, Janacsek, Fiser, and Nemeth (2012) observed an age-related decrement at 12 years in implicit learning of probabilistic sequences of visual-spatial patterns on the Alternating Serial Reaction Time task, administered to participants ranging in age from 4 to 85 years. In a series of meta-analyses, Hamrick, Lum, and Ullman (2018) found evidence suggesting lesser involvement of procedural memory and greater involvement of declarative memory in adult L2-learners with low levels of L2-experience, in contrast to child L1-learners and adult L2-learners with high levels of experience who show evidence for involvement of procedural memory in grammatical processing. Other recent work suggests that disrupting prefrontal cortical activity through cathodal transcranial direct current stimulation boosts motor sequence learning (Zhu, Yeung, Poolton, Lee, Leung, \& Masters, 2015), which is thought to rely on the same neural substrate as statistical learning of phonological and grammatical information (Ullman, 2001). However, it remains to be seen whether direct benefits from suppression of prefrontal activity can be observed for language learning. 


\section{RECONSIDERING THE LESS-IS-MORE HYPOTHESIS 8}

Reliance on multiword processing. An alternative proposal is that children are more likely than adults to learn words and syntactic relations from multiword units (Arnon \& Christiansen, 2017; Arnon, McCauley, \& Christiansen, 2017), either because limited cognitive capacity and lack of conceptual knowledge lead children to under-segment the input or because chunking leads to different learning outcomes in children. Unlike adults, children learn concepts at the same time as they learn grammatical relations, resulting in lexical representations that include co-occurring grammatical morphemes (e.g., in Spanish, gender-marked articles co-occurring with nouns, as in el libro [book] or la mano [hand]). Overlapping representations of multiword units and their constituent morpho-syntactic components enhance children's ability to make accurate predictions as language unfolds over time. The idea that learning benefits can be derived from larger units is directly at odds with Newport's (1990) original idea that capacity limitations promote learning from smaller units. However, because the process of chunking itself is unlikely to differ for children and adults, this proposal places the origin of age-of-acquisition effects within the realm of learning biases, and not capacity limitations.

\section{Empirical evaluations of the Less-is-More hypothesis}

The Less-is-More hypothesis has considerable intuitive appeal due to consensus that processing capacity increases with age, as indicated by developmental studies of working memory, executive functioning, processing speed, and nonverbal intelligence (Anderson, 2002; Cowan, 2016; Fry \& Hale, 2000). Yet, for this hypothesis to provide a compelling account of age-of-first-exposure effects in language learning, it is necessary to demonstrate that children are indeed superior language learners, that disruption of 


\section{RECONSIDERING THE LESS-IS-MORE HYPOTHESIS 9}

cognitive capabilities supports language learning, and that increased cognitive capacity is associated with reduced learning.

Correlational studies. In Johnson and Newport's (1989) seminal study, a link between age-of-exposure and L2 grammaticality-judgments was evident only for learners exposed to English (L2) prior to puberty. Learners exposed to English after puberty did not show such a link and exhibited considerable variability in performance. This discontinuity was interpreted as suggesting that once mechanisms required for optimal language learning are no longer accessible after the critical period, language learning is governed by domaingeneral mechanisms that are susceptible to individual differences in abilities and circumstances. However, other studies have documented more continuous age-of-firstexposure effects on L2-learning that are incompatible with a sharply defined critical period offset around puberty. For instance, in a large-scale study utilizing U.S. census data from 2.3 million immigrants with Spanish or Chinese L1-backgrounds, Hakuta, Bialystok, and Wiley (2003) failed to find evidence of a discontinuity in self-reported English attainment that could be attributed to the offset of a putative critical period. In a replication study using Johnson and Newport's (1989) test materials with Spanish-speaking learners of English, Birdsong and Molis (2001) observed minimal age-of-first-exposure effects in learners exposed to English prior to age 17 and pronounced age-of-first-exposure effects in older learners, perhaps reflecting the influence of confounding factors such as the amount of daily exposure to English vs. Spanish, level of education, or motivation to learn English. Given the discrepancy between their results and those of Johnson and Newport (1989), Birdsong and Molis (2001) suggested that the relationship between age-of-first-exposure and L2-learning might vary as a function of L1-L2 pairings as prior language experience 
modulates the cognitive challenges associated with learning a new language. Even more challenging to the Less-is-More hypothesis was their observation that some late learners achieve native-like performance in L2 grammaticality-judgments, which demonstrates that cognitive maturity does not create an insurmountable obstacle to L2-learning success.

The existing literature has a range of limitations. First, as indicated above, studies are often severely underpowered, which increases the likelihood that the discrepancies are simply due to statistical noise (Hartshorne et al., 2018; Vanhove, 2013), or based on less reliable self-report data. Second, correlations between age-of-first-exposure and L2attainment do not prove the existence of a critical period per se nor do they constitute sufficient evidence for the Less-is-More hypothesis because age-of-first-exposure is almost always confounded with other factors that conspire to promote L2-acquisition. Individuals with early exposure are likely to receive a much larger amount of L2-exposure over time than individuals with late L2-exposure: They are likely to experience longer periods of formal education in the L2 (Flege, Yeni-Komshian, \& Liu, 1999), greater amounts of daily L2-use (Flege, Munro \& MacKay, 1995; Flege, Frieda \& Nozawa, 1997), a higher degree of literacy in the L2 (Elley \& Mangubhai, 1983; Jia \& Aaronson, 2003), and stronger motivation to conform linguistically with peers (Jia \& Aaronson, 2003). Furthermore, age of L2-exposure tends to correlate with dominance of and amount of experience with the L1, which may result in a greater interference from the L1 in late L2-learners. Indeed, Flege et al. (1995) observed greater L1 (Italian) accent as a function of age of L2-exposure to English — a pattern similar to the findings for grammaticality judgments described above. At the same time, L1-use predicted the degree of accent over and above the effect of ageof-first-exposure. Although infrequently emphasized, early L2-exposure is often 


\section{RECONSIDERING THE LESS-IS-MORE HYPOTHESIS 11}

accompanied by L1-attrition, with some individuals undergoing a dominance shift and potentially losing their L1-skills (Fillmore, 1991; Jia \& Aaronson, 2003, but see Schmid, 2007). Indeed, children growing up in bilingual households in the U.S. often do not acquire proficiency in both languages. Frequently, such children have only passive knowledge of their heritage language while attaining full command of English. Recent longitudinal work in bilingual Spanish-English communities of South Florida indicates trade-offs between children's usage of English and their ability to speak Spanish as a heritage language (Hoff \& Ribot, 2017). Factors such as the presence of school-age siblings and the tendency to engage in conversational code switching (e.g., using English to answer questions posed in Spanish) impede acquisition of Spanish, despite substantial daily exposure to the language from birth (Ribot, Hoff, \& Burridge, 2018). Thus, substantial evidence suggests that the link between age of L2-exposure and ultimate attainment may arise from a host of factors unrelated to gains in cognitive capacity (Hartshorne et al., 2018; Mayberry \& Kluender, 2017).

Quasi-experimental studies. Acknowledging that the presence of confounding factors necessitates moving beyond correlations, researchers have tested the Less-is-More hypothesis using quasi-experimental designs that compare performance of adults and children on language learning tasks. The main prediction is that children should demonstrate superior overall learning or at least exhibit some qualitative aspects of learning that are considered advantageous for learning of linguistic structure, like regularization of unpredictable variation or decomposition of complex constructions.

In a series of studies utilizing artificial languages, Hudson Kam and Newport (2005; 2009) compared children and adults learning artificial languages where the distribution of 
determiners followed a consistent or inconsistent pattern in the input. Children regularized inconsistent input by using one determiner at the expense of others (Hudson Kam \& Newport, 2005). Adults, in contrast, only regularized input with very complex patterns of inconsistency (Hudson Kam \& Newport, 2009). Such findings were taken as support for the view that children play a crucial role in systematizing and regularizing inconsistent language input as it is transmitted over generations. However, Perfors (2012a, 2016) showed that when adults experienced less pressure to be "correct" they regularized the input just as much as children-leaving open the possibility that the observed differences between adults and children in regularization may be due to differences in pragmatic and social assumptions about the goals of the task and the nature of the encountered variation, rather than cognitive limitations.

Experimental studies. To avoid confounding factors that differentially affect performance of children vs. adults in quasi-experimental studies, researchers have scrutinized the Less-is-More hypothesis through direct experimental manipulations of cognitive capacity. Thus, to test the prediction that limiting working-memory capacity facilitates learning of form-meaning mappings, Cochran, MacDonald and Parault (1999) taught modified ASL signs to naïve adults while manipulating concurrent load (i.e., requiring participants to count tones while attempting to learn signs), and compared their performance to a "no load" control group. Although the "no load" group exhibited faster learning of the signs, they tended to make holistic errors in a generalization test, by producing signs exactly as they were learned rather than adjusting them to fit new contexts. Participants in the "load" condition made few holistic errors, but omitted individual components of signs and showed worse performance overall. In another experiment, 
Cochran et al. had participants practice whole signs or parts of signs. Participants who practiced whole signs tended to produce holistic errors, which suggested that they failed to decompose the signs into constituent morphemes, as predicted by the Less-is-More hypothesis. Note, however, that Rohde and Plaut (2003) heavily critiqued this study as providing little evidence that cognitive load facilitates decomposition of signs into morphemes, instead emphasizing the noisy and overall poor performance of the "load" group relative to the "no-load" group.

Another manipulation of cognitive resources involves boosting cognitive capacity by making tasks easier. Hudson Kam and Chang (2009) showed that the amount of regularization decreased when learners were given flashcards with words printed on them to reduce demands on lexical retrieval. Yet, conversely, manipulations designed to increase cognitive load did not increase regularization: When Perfors (2012b) tested adults under six different load conditions as they learned an artificial language with complex patterns of inconsistency (modeled after Hudson Kam \& Newport, 2009), "load” groups were no more likely to regularize determiner use than a "no load" control group. Indeed, the data showed a non-significant trend in the opposite direction, with less regularization under concurrent load, counter to predictions of the Less-is-More hypothesis.

Computational evidence. Although numerous computational models have successfully simulated language-learning trajectories (Freudenthal, Pine, Aguado-Orea \& Gobet, 2007; Mintz, 2003; Redington, Chater, \& Finch, 1998), only a few have manipulated processing capacity directly. In a seminal study, Elman (1993) trained a recurrent neural network to learn a semi-artificial language consisting of sentences with verbs in various grammatical constructions. The sentences differed in complexity in that 
they could contain zero, one, or multiple embedded units (e.g., relative clauses). The network was trained to predict the next word in the sentence, a task that required "knowledge" of the underlying grammar. While learning outcomes were unsatisfactory when the network was trained on the full corpus of sentences, grammar learning was more successful when two types of changes were independently introduced: an incremental input manipulation (discussed below) and a capacity manipulation, which was accomplished by gradually increasing the number of words that were held in memory through the recurrent feedback connections or by gradually enlarging the initially small network. Elman's models were taken as evidence that simplified input or capacity limitations can lead to superior learning outcomes.

However, subsequent attempts to replicate the benefit of "starting small" cast doubt on the generality of Elman's computational account of the Less-is-More hypothesis. After failing to replicate Elman's modeling results, Rohde and Plaut (1999) outlined problems associated with pre-training recurrent neural networks on only some types of form-meaning mappings or on some local dependencies. In such cases the network may show effects of catastrophic interference where patterns of connectivity among hidden units become entrenched during learning, hindering subsequent learning that requires establishing a different pattern of connectivity. Further doubt about the benefits of capacity limitations comes from statistical models: Perfors (2012b) explored effects of capacity limitations by simulating learning as a process of Bayesian inference. She demonstrated that when capacity is diminished, regularization takes place only if an a priori bias towards regularization is present, which suggests that regularization is not a result of capacity limitations per se. 
In sum, despite its intuitive appeal, the empirical evidence for the Less-is-More hypothesis with respect to various aspects of cognitive capacity is weak: Correlational studies suggest continuous age-of-exposure effects that either extend over the life span or suggest an offset of the critical period at a time later than when cognitive capacity is fully established. They also leave open the possibility that other individual and situational factors can shape task demands and learning trajectories in different ways for children and adults. At the same time, experimental and computational evidence for regularization and decomposition arising from direct manipulations of working-memory capacity and cognitive control remains equivocal. Moreover, it stands to reason that regularization and decomposition, rather than being beneficial, may in fact be detrimental for language learning, especially for complex morphological systems. For example, in Russian singular nouns, markers for six cases vary according to three declension paradigms comprising feminine nouns ending in $/-\mathrm{a} /$ or $/-\mathrm{ya} /$ in the nominative, masculine and neuter nouns, and feminine nouns ending in palatalized consonants in the nominative. At the same time, adjectives and past-tense verbs must agree with the grammatical gender of their referents (masculine, feminine, or neuter). This complexity appears unpredictable at the outset of learning until sufficient information from the relevant probabilistic co-occurrence patterns of the various gender and case cues has been accrued. If children were prone to regularize the system by relying on the use of one declension paradigm or one gender agreement pattern at the expense of the others, it would impede acquisition of the underlying declension system (Kempe \& Brooks, 2014). Yet empirical evidence suggests that children readily acquire many aspects of these complex systems as early as 3 years of age (Kempe, Brooks, Mironova \& Fedorova, 2003). 
Children's increased propensity for decomposition and regularization has been assumed to shape emergence of language structure, for example, when children are credited with introducing syntactically motivated spatial morphemes into a newly emerging language like Nicaraguan Sign Language (Senghas \& Coppola, 2001; Senghas et al., 2004). How can this assumption be reconciled with the paucity of empirical support for a link between children's capacity limitations and increased regularization and decomposition? Insights may come from iterated language learning studies, which are taken as laboratory simulations of changes that occur during language transmission. Such studies demonstrate that creation of arbitrary, compositional signs is exactly what would be expected if a signaling system, such as an emerging sign language, were transmitted by successive generations of users. Kirby, Tamariz, Cornish, and Smith (2015) showed that compositional grammatical structure, which entails systematically linking elements of the form with dimensions of meaning, emerges when signaling systems are subjected to the dual pressures of having to be learnable and communicatively expressive. As these two conditions are met in the context of creating a new sign language, subsequent generations of learners of an initially holistic and idiosyncratic communication system would be expected to introduce compositional grammatical structure, regardless of their age. Hence, in the case of Nicaraguan Sign Language, although the subsequent learners happened to be children, there is no evidence that it was their cognitive immaturity, rather than their position in the transmission chain, that led to their decomposing and regularizing the signs.

\section{The 'More-Is-More' hypothesis}

In contrast to the paucity of evidence in support of the Less-is-More hypothesis, there has been intensive investigation of individual differences in processing capacity in 
relation to L1- and L2-learning outcomes that support a More-is-More account. Here research has attempted to link individual differences in language learning with several interacting components of capacity, including phonological short-term memory, working memory, and executive functioning (Kidd, Donnelly, \& Christiansen, 2018).

Predicting L1-learning outcomes. Many studies investigating individual differences in language learning have focused on phonological short-term memory capacity, often assessed via nonword repetition tasks that require individuals to repeat back nonsense words of varying lengths (Gathercole, Willis, Baddeley, \& Emslie, 1994). In an early study of word learning in 5-year-olds, Gathercole and Baddeley (1990) observed that children with high nonword repetition ability outperformed their peers in learning names of unfamiliar toys. Using a longitudinal design to determine the direction of the relationship, Gathercole Willis, Emslie, and Baddeley (1992) found significant crosslagged correlations between nonword repetition and L1-vocabulary size of children tested on three occasions between 4 and 8 years of age, with nonword repetition scores at earlier time points predicting vocabulary size at later time points. Gathercole, Hitch, Service, and Martin (1997) further demonstrated a significant relationship between nonword repetition and word learning in 5-year-olds after controlling for nonverbal ability and vocabulary size, which led them to conclude that the phonological loop (i.e., storage capacity) might serve as a language-learning device (Baddeley, Gathercole, \& Papagno, 1998). However, subsequent replications with sizeable samples have suggested that the relationship may be reversed, i.e., having a larger vocabulary may enhance short-term storage of linguistic information (Melby-Lervåg, Lervåg, Lyster, Klem, Hagtvet, \& Hulme, 2012). While the direction of causality is under debate (MacDonald, 2016), the relationship between 
memory measures, such as nonword or sentence repetition, and language skills, such as vocabulary, is a positive one (Klem, Melby-Lervåg, Hagtvet, Lyster, Gustafsson, \& Hulme, 2015). Indeed, children with Developmental Language Disorder (also known as Specific Language Impairment) exhibit deficits to such an extent that nonword repetition (Bishop, North, \& Donlan, 1996; Estes, Evans, \& Else-Quest, 2007), sentence repetition (ContiRamsden, Botting, \& Faragher, 2001), and sentence recall (Archibald \& Joanisse, 2009) are viewed as useful behavioral markers for the disorder. Extending findings beyond L1acquisition, there is considerable evidence that verbal working-memory capacity correlates with L1-comprehension throughout the lifespan — see Daneman and Merikle (1999) for a meta-analysis of sentence-processing studies and Carretti Borella, Cornoldi, and De Beni (2009) for a meta-analysis of studies testing individuals with impaired reading comprehension.

Notably, the link between cognitive capacity and language skills in children extends beyond verbal measures, as meta-analytic reviews involving large numbers of studies and participants implicate deficits in nonverbal processing capacity in the etiology of Developmental Language Disorder. These include deficits in sustained attention (Ebert \& Kohnert, 2011), visual-spatial working memory (Vugs, Cuperus, Hendriks, \& Verhoeven, 2013), procedural learning (Lum, Conti-Ramsden, Morgan, \& Ullman, 2014), cognitive control and executive functioning (Pauls \& Archibald, 2016), and nonverbal intelligence (Gallinat \& Spaulding, 2014). Such relationships are evident in children at risk of language delays, as in a recent study of children from low-income families comprising the "no treatment" group of the Early Head Start Research and Evaluation project (Brooks, Flynn, \& Ober, 2018), where individual differences in infants' sustained attention at age 14 
months predicted vocabulary size at age 36 months after controlling for other significant variables.

Predicting L2-learning outcomes: Consistent with findings from L1-acquisition, studies of L2-acquisition provide support for the More-is-More account. In an early study involving Finnish school children, Service (1992) observed that students' ability to repeat back English-sounding nonwords at age 9 predicted their English proficiency at age 11. Likewise, in a study of 12-year-old Chinese students learning English as an L2, Cheung (1996) reported a significant correlation between nonword span (i.e., the maximum length of a sequence of two-syllable nonwords that could be repeated back correctly) and the number of trials required to learn English words. Extending the work to adults, Papagno, Valentine, and Baddeley (1991) and Ellis and Sinclair (1996) demonstrated that engaging participants in articulatory suppression (e.g., requiring them to count from one to five in a continuous cycle) interfered with L2-learning, presumably by disrupting short-term memory storage. Note that this finding is in direct contradiction to predictions form the Less-is-More hypothesis. Moreover, Ellis and Beaton (1993) observed that techniques like rote rehearsal and imitation that help adult learners to maintain novel words in short-term memory facilitated L2-learning. Likewise, nonword repetition and phonological sequence learning have been shown to correlate with individual differences in L2-vocabulary acquisition (Speciale, Ellis, \& Bywater, 2004).

Other studies have linked verbal working-memory capacity with L2-sentence processing; see Linck, Osthus, Koeth, and Bunting (2014) for a meta-analytic review. In a study of Japanese learners of English, Miyake and Friedman (1998) linked verbal workingmemory capacity with L2-comprehension specifically with regards to using word order 
and subject-verb agreement as cues to grammatical roles. Similarly, using a miniature artificial language, Ellis and Schmidt (1998) found learners' ability to maintain verbal information in memory to predict their accuracy in grammaticality-judgments for sentences with long-distance dependencies (subject-verb agreement for transitive sentences with SOV word-order). Other studies of individual differences in L2-learning have included measures of nonverbal intelligence and auditory sequence learning as indices of processing capacity (Andringa, Olsthoorn, van Beuningen, Schoonen, \& Hulstijn, 2012; Brooks \& Kempe, 2013; Brooks, Kwoka, \& Kempe, 2017; Granena, 2013; Kempe \& Brooks, 2011); these studies collectively provide support for the view that processing capacity may be a fundamental component of language learning aptitude (Grigorenko, Sternberg, \& Ehrman, 2000; Linck et al., 2013).

The More-is-More hypothesis that individuals with greater cognitive capacity are better language learners leads to the prediction that when input and learning conditions are similar, adults should learn more efficiently than children, and older children should learn more efficiently than younger children. This prediction is supported by a number of studies. Snow and Hoefnagel-Höhle (1978) compared native English speakers, ranging in age from 3 years to adulthood, in their learning of Dutch, using measures of pronunciation, auditory discrimination, morphology, sentence repetition, translation, vocabulary knowledge, comprehension and production fluency. In all tests except pronunciation, younger children performed worst and adolescents performed best, closely followed by adults. d'Ydewalle and Van de Poel (1999) investigated incidental L2-learning from subtitled television programs and found no learning benefits for children compared to adults. Using an artificial language, Braine et al. (1990) demonstrated that when learners were exposed to exactly the 
same amount of input adults outperformed children in acquiring grammatical gender and case marking (see also Brooks et al., 1993). Similarly, Saffran (2001) observed adults outperforming children in registering statistical regularities associated with word classes and phrase structure rules. This and other studies showing a slower rate of L2-learning in children than adults (e.g., Krashen, Scarcella, \& Long, 1982) led Saffran to suggest that due to their limited processing capacity, children might need more input than adults to register statistical regularities, or that phrase structure rules might not be subject to critical period effects. We would argue that the more parsimonious interpretation is that learners with greater capacity are at an advantage in acquiring many aspects of language.

\section{Less-is-More redux: Less knowledge allows children to consider a broader range of}

\section{hypotheses}

While the evidence for beneficial effects of processing limitations on language learning is unconvincing, different learning outcomes may arise from differences between children's and adult's prior knowledge. In contrast to Newport's hypothesis that limited processing capacity restricts hypothesis space, thus giving young children access to fewer potential rules, Gopnik, Griffiths, and Lewis (2015) proposed that limited prior knowledge allows children to entertain a more open-ended and less constrained set of hypotheses. For learning in non-linguistic domains, this idea has been supported in studies involving a "blicket" detector, where participants had to determine which settings made an unknown object introduced as “blicket” emit sounds (Griffiths, Sobel, Tenenbaum, \& Gopnik, 2011; Lucas, Bridgers, Griffiths, \& Gopnik, 2014): Children were more likely than adults to grasp complex causal rules that adults may have overlooked due to prior knowledge and experience biasing their hypotheses. Relatedly, Ellis (2002) has suggested that the 
progressive tuning of attention over the course of language learning may decrease sensitivity to other possible patterns of variation - a mechanism that has also been invoked to explain the perceptual magnet effect in speech perception (Kuhl \& Iverson, 1995).

McDonough, Choi, and Mandler (2003) explored how categorization biases change with development and whether infants are indeed more flexible learners than adults. In oddity detection/preferential looking tasks requiring participants to categorize exemplars of contrasting spatial concepts, English-speaking adults and infants were successful in distinguishing scenes depicting the familiar English lexical contrast between 'in' for containment (e.g. 'corks plugged into bottles') vs. 'on' for support (e.g. 'foam letters placed standing up on a surface'). However, when presented with scenes depicting spatial relations that exemplified the unfamiliar Korean lexical contrast between tight-fit ' $k$ kita' (e.g. 'keys inserted into tight-fitting keyholes') vs. loose-fit 'nohta' (e.g. 'blocks placed into a loosefitting sack'), infants from English-speaking homes, infants from Korean-speaking homes, and Korean adults all showed a strong preference to select the exemplar of the familiar concept at test, whereas English-speaking adults performed at chance due to interference from their pre-existing knowledge of English spatial terms. Infants, unlike adults, were flexible in carving out spatial categories that matched either the English or Korean lexicalization patterns.

Other research has emphasized how prior learning enhances subsequent processing through mechanisms such as priming. Even at early stages of L1-acquisition, infants exhibit learning trajectories that obey power-law functions indicative of the beneficial effect of practice (Ninio, 2006). Similarly, in L2-learning and in literacy acquisition, growth trajectories reflect the benefits of prior learning in improving the accuracy of 
predictions and facilitating subsequent learning, with advantages of more efficient processing accumulating over time (Ellis, 2012; Stanovich, 1986). As learners develop facility in processing information in a given domain, their hypotheses become more constrained, which can contributes to L1-L2 transfer but also to interference which can hinder L2-learning (Ellis, 2002; McDonough et al., 2003).

\section{Less-is-More redux again: Less complex input benefits language learning}

In his neural network simulations of the Less-is-More hypothesis, Elman (1993) also explored whether scaffolded, simplified input might be beneficial at early stages of learning. Although input manipulations, which involved exposing the network to a subset of form-meaning mappings before expanding the input to encompass the full range of mappings, are not comparable to input restrictions that arise from children's memory limitations (Rohde \& Plaut, 1999), it is worth considering whether reducing the complexity of the input facilitates language learning.

Direct tests of this formulation of Less-is-More hypothesis come from experimental studies that manipulated the complexity of input at different stages of learning, with the purpose of determining whether simpler input at the outset facilitates subsequent processing of more complex input. In Kersten and Earles (2001), naïve adults attempted to learn a miniature artificial language consisting of tri-syllabic words combined into threeword sentences. In the incremental-input group, the first block of training consisted of oneword sentences, the second block of two-word sentences, and the final block of three-word sentences, whereas the control group received three-word sentences from the outset. Across a set of experiments, the incremental-input group showed superior learning, suggesting that reducing the complexity of the input at early stages was advantageous for learning 
vocabulary and grammatical morphology (see also Conway, Ellefson, \& Christiansen, 2003).

To evaluate this version of the Less-is-More hypothesis requires examining what the input is actually like for children and whether it bears resemblance to the input manipulations used in the above-mentioned experimental studies. There is considerable evidence that CDS registers, although variable across languages and cultures, tend to be characterized by a number of specific features: prosodic patterns are exaggerated, sentences and clauses are shorter, vocabulary is more repetitive, and novel words tend to occur in salient positions, such as at the end of utterances (Soderstrom, 2007). Moreover, in CDS, a substantial number of words are produced in isolation, which may help children identify word boundaries, detect statistical regularities in the input, and learn word meanings (Brent \& Siskind, 2001; Lew-Williams, Pelucchi, \& Saffran, 2011; Ninio, 2016). Infants are differentially responsive to CDS and prefer to listen to it (Cooper \& Aslin, 1990; Fernald, 1985; Werker, Pegg, \& McLeod, 1994). Ma, Golinkoff, Houston, and Hirsh-Pasek (2011) observed that 21-month-olds learned words more readily from CDS than from adult-directed speech (ADS), although by age 27 months toddlers learned just as readily from ADS.

Other aspects of CDS have been shown to facilitate learning. For instance, children appear to benefit from the use of diminutives suffixes, a derivation which mainly serves an affective function, yet in some languages creates clusters of nouns with similar morphophonological properties, rendering grammatical categories (e.g., gender or case) more transparent and easier to learn (Savickienè, Kempe, \& Brooks, 2009; Ševa et al., 2007). More generally, children benefit when CDS builds on what they have already said or have 
in mind (Che, Brooks, Alarcon, Yannaco, \& Donnelly, 2017; Tamis-LeMonda, Bornstein, \& Baumwell, 2001); such input may be impactful because it is specifically tailored to their limited attention spans.

Several studies have explored whether features of CDS might be beneficial for L2learning. For example, placing target words in salient utterance-final position, as is typical for CDS, has been shown to enhance learning of Chinese vocabulary (Golinkoff \& Alioto, 1995). Likewise, providing frequent diminutives in the input may facilitate learning of Russian morphology (Brooks, Kempe, \& Donachie, 2011; Kempe \& Brooks, 2001) and word segmentation (Kempe, Brooks, \& Gillis, 2005).

However, even in the context of CDS, there is evidence favoring a More-is-More account. In assessing the impact of variable input on language outcomes, a large body of work has compared children of varying socio-economic backgrounds where disparities have been described as a "30 million word gap" in input directed toward low-income children (Hart \& Risley, 2003; Hoff, 2003). Research findings emphasize the importance of higher quality input, exemplifying a more diverse range of vocabulary and grammatical constructions, in facilitating language growth (Huttenlocher, Vasilyeva, Cymerman, \& Levine, 2002; Pan, Rowe, Singer, \& Snow, 2005; Rowe, 2012), and the benefits of shared book reading and other activities that elicit more complex speech (Raikes et al., 2006; Weigel, Martin, \& Bennett, 2006). Extending the work to adults, Dąbrowska and Street (2006; Street \& Dąbrowska, 2010) have similarly linked socio-economic variability in L1attainment with input-related factors. Thus, while less complex input may facilitate language learning in infancy, subsequent growth requires gradual expansion in the complexity of CDS, commensurate with learners' needs and abilities. 


\section{Conclusions}

Various conceptualizations of the original idea that limited processing capacity helps children to acquire the complexities of human languages and may explain their putative superiority in L2-learning have received little direct empirical support. Instead, the literature provides considerable evidence favoring a More-is-More account where increased cognitive capacity facilitates L1 - and L2-acquisition, while indicating that lesser capacity is a risk factor for Developmental Language Disorder. Counter to the view that limited capacity filters the input and thus serves to constrain hypotheses children's limited knowledge may minimize interference from prior biases, allowing younger L2-learners to entertain a broader range of hypotheses than older L2-learners. Finally, we explored whether simplification of the input might aid language learning and found evidence of benefits from some specific features of CDS. At the same time, research on individual differences suggests that, as learning progresses, the lexical and grammatical complexity of input needs to increase appropriately to accelerate further language learning. We therefore conclude that immature cognitive processing capacity, a constrained hypothesis space, and reduced input complexity are not suitable explanations for the link between ageof-exposure and individual differences in language attainment. 


\section{References}

Anderson, P. (2002). Assessment and development of executive function (EF) during childhood. Child Neuropsychology, 8(2), 71-82.

https://doi.org/10.1076/chin.8.2.71.8724

Andringa, S., Olsthoorn, N., van Beuningen, C., Schoonen, R., \& Hulstijn, J. (2012). Determinants of success in native and non-native listening comprehension: An individual differences approach. Language Learning, 62(S2), 49-78. https://doi.org/10.1111/j.1467-9922.2012.00706.x

Archibald, L.M., \& Joanisse, M.F. (2009). On the sensitivity and specificity of nonword repetition and sentence recall to language and memory impairments in children. Journal of Speech, Language, and Hearing Research, 52(4), 899-914. https://doi.org/10.1044/1092-4388(2009/08-0099)

Arnon, I., \& Christiansen, M. H. (2017). The role of multiword building blocks in explaining L1-L2 differences. Topics in Cognitive Science, 9(3), 621-636. https://doi.org/10.1111/tops.12271

Arnon, I., McCauley, S.M., \& Christiansen, M.H. (2017). Digging up the building blocks of language: Age-of-acquisition effects for multiword phrases. Journal of Memory and Language, 92, 265-280. https://doi.org/10.1016/j.jml.2016.07.004

Baddeley, A., Gathercole, S., \& Papagno, C. (1998). The phonological loop as a language learning device. Psychological Review, 105(1), 158-173. http://dx.doi.org/10.1037/0033-295X.105.1.158 
Birdsong, D. \& Molis, M. (2001). On the evidence for maturational constraints in secondlanguage acquisition. Journal of Memory and Language, 44, 235-249. https://doi.org/10.1006/jmla.2000.2750

Bishop, D.V., North, T., \& Donlan, C. (1996). Nonword repetition as a behavioural marker for inherited language impairment: Evidence from a twin study. Journal of Child Psychology and Psychiatry, 37(4), 391-403. https://doi.org/10.1111/j.14697610.1996.tb01420.x

Bjorklund, D.F. (2018). A metatheory for cognitive development (or "Piaget is Dead" revisited). Child Development. [advanced e-pub] https://doi.org/10.1111/cdev.13019

Braine, M.D.S., Brody, R.E., Brooks, P.J., Sudhalter, V., Ross, J.A., Catalano, L., \& Fisch, S.M. (1990). Exploring language acquisition in children with a miniature artificial language: Effects of item and pattern frequency, arbitrary subclasses, and correction. Journal of Memory and Language, 29(5), 591-610. https://doi.org/10.1016/0749-596X(90)90054-4

Brent, M.R., \& Siskind, J.M. (2001). The role of exposure to isolated words in early vocabulary development. Cognition, 81(2), B33-B44. https://doi.org/10.1016/S0010-0277(01)00122-6

Brooks, P.J., Braine, M.D., Catalano, L., Brody, R.E., \& Sudhalter, V. (1993). Acquisition of gender-like noun subclasses in an artificial language: The contribution of phonological markers to learning. Journal of Memory and Language, 32(1), 76-95. https://doi.org/10.1006/jmla.1993.1005 
Brooks, P.J., Flynn, R.M., \& Ober, T.M. (2018). Sustained attention in infancy impacts vocabulary acquisition in low-income toddlers. In A.B. Bertolini and M.J. Kaplan (Eds.), Proceedings of the 42nd Annual Boston University Conference on Language Development (pp. 86-99). Somerville, MA: Cascadilla Press. Retrieved from: http://www.lingref.com/bucld/42/BUCLD42-07.pdf

Brooks, P.J. \& Kempe, V. (2013). Individual differences in adult foreign language learning: The mediating effect of metalinguistic awareness. Memory \& Cognition, 41(2), 281-296. https://doi.org/10.3758/s13421-012-0262-9

Brooks, P.J., Kempe, V. \& Donachie, A. (2011). Second language learning benefits from similarity in word endings: Evidence from Russian. Language Learning, 61(4), 1142-1172. https://doi.org/10.1111/j.1467-9922.2011.00665.x

Brooks, P.J., Kwoka, N., \& Kempe, V. (2017). Distributional effects and individual differences in L2 morphology learning. Language Learning, 67(1), 171-207. https://doi.org/10.1111/lang.12204

Carretti, B., Borella, E., Cornoldi, C., \& De Beni, R. (2009). Role of working memory in explaining the performance of individuals with specific reading comprehension difficulties: A meta-analysis. Learning and Individual Differences, 19(2), 246251. https://doi.org/10.1016/S0010-0277(01)00122-6

Che, E.S., Brooks, P.J., Alarcon, M.F., Yannaco, F.D., \& Donnelly, S. (2018) Assessing the impact of conversational overlap in content on child language growth. Journal of Child Language, 45(1), 72-96. https://doi.org/10.1017/S0305000917000083

Cheng, Q., Halgren, E., \& Mayberry R. (2018). Effects of early language deprivation: Mapping between brain and behavioral outcomes. In A.B. Bertolini and M.J. 
RECONSIDERING THE LESS-IS-MORE HYPOTHESIS 30

Kaplan (Eds.), Proceedings of the 42nd Annual Boston University Conference on Language Development (pp. 140-152). Somerville, MA: Cascadilla Press.

Retrieved from: http://www.lingref.com/bucld/42/BUCLD42-11.pdf

Cheung, H. (1996). Nonword span as a unique predictor of second-language vocabulary language. Developmental Psychology, 32(5), 867-873.

http://dx.doi.org/10.1037/0012-1649.32.5.867

Chrysikou, E.G., Novick, J.M., Trueswell, J.C., \& Thompson- Schill, S.L. (2011). The other side of cognitive control: Can a lack of cognitive control benefit language and cognition? Topics in Cognitive Science, 3(2), 253-256.

https://doi.org/10.1111/j.1756-8765.2011.01137.x

Cochran, B.P., McDonald, J. L., \& Parault, S.J. (1999). Too smart for their own good: The disadvantage of a superior processing capacity for adult language learners. Journal of Memory and Language, 41(1), 30-58. https://doi.org/10.1006/jmla.1999.2633

Connor, C.M., Craig, H.K., Raudenbush, S.W., Heavner, K., \& Zwolan, T.A. (2006). The age at which young deaf children receive cochlear implants and their vocabulary and speech-production growth: is there an added value for early implantation? Ear and Hearing, 27(6), 628-644. https://doi.org/10.1097/01.aud.0000240640.59205.42

Conti-Ramsden, G., Botting, N., \& Faragher, B. (2001). Psycholinguistic markers for specific language impairment (SLI). Journal of Child psychology and Psychiatry, 42(6), 741-748. https://doi.org/10.1017/S0021963001007600 


\section{RECONSIDERING THE LESS-IS-MORE HYPOTHESIS 31}

Conway, C.M., Ellefson, M. R., \& Christiansen, M.H. (2003). When less is less and when Less is More: Starting small with staged input. In Proceedings of the 25th Annual Conference of the Cognitive Science Society (pp. 270-275). Mahwah, NJ:

Erlbaum. Retrieved from: https://escholarship.org/uc/item/50m4m95z

Cooper, R.P., \& Aslin, R.N. (1990). Preference for infant- directed speech in the first month after birth. Child Development, 61(5), 1584-1595. https://doi.org/10.1111/j.1467-8624.1990.tb02885.x

Cowan, N. (2016). Working memory maturation: Can we get at the essence of cognitive growth? Perspectives on Psychological Science, 11(2), 239-264. https://doi.org/10.1177/1745691615621279

Curtiss, S. (1977). Genie: A psycholinguistic study of a modern day “wild child.” New York: Academic Press.

d'Ydewalle, G., \& Van de Poel, M. (1999). Incidental foreign-language acquisition by children watching subtitled television programs. Journal of Psycholinguistic Research, 28(3), 227-244. https://doi.org/10.1023/A:1023202130625

Dąbrowska, E., \& Street, J. (2006). Individual differences in language attainment: Comprehension of passive sentences by native and non-native English speakers. Language Sciences, 28(6), 604-615. https://doi.org/10.1016/j.langsci.2005.11.014

Daneman, M., \& Merikle, P.M. (1996). Working memory and language comprehension: A meta-analysis. Psychonomic Bulletin \& Review, 3(4), 422-433. https://doi.org/10.3758/BF03214546 
Ebert, K.D., \& Kohnert, K. (2011). Sustained attention in children with primary language impairment: A meta-analysis. Journal of Speech, Language, and Hearing Research, 54(5), 1372-1384. https://doi.org/10.1044/1092-4388(2011/10-0231)

Elley, W.B., \& Mangubhai, F. (1983). The impact of reading on second language learning. Reading Research Quarterly, 19(1), 53-67. http://www.jstor.org/stable/747337

Ellis, N.C. (2002). Reflections on frequency effects in language processing. Studies in Second Language Acquisition, 24(2), 297-339. http://www.jstor.org/stable/747337

Ellis, N.C. (2012). What we can count in language, and what counts in language acquisition, cognition, and use? In S. Th. Gries \& D. Divjak (Eds.) Frequency effects in language learning and processing (pp. 7-33). Berlin: Walter de Gruyter.

Ellis, N.C., \& Beaton, A. (1993). Factors affecting the learning of foreign language vocabulary: Imagery keyword mediators and phonological short-term memory. The Quarterly Journal of Experimental Psychology: Section A, 46(3), 533-558. https://doi.org/10.1080/14640749308401062

Ellis, N.C., \& Schmidt, R. (1997). Morphology and longer distance dependencies: Laboratory research illuminating the A in SLA. Studies in Second Language Acquisition, 19(2), 145-171. https://www.jstor.org/stable/44488681

Ellis, N.C., \& Sinclair, S.G. (1996). Working memory in the acquisition of vocabulary and syntax: Putting language in good order. The Quarterly Journal of Experimental Psychology: Section A, 49(1), 234-250. https://doi.org/10.1080/713755604 
Emmorey, K., Bellugi, U., Friederici, A., \& Horn, P. (1995). Effects of age of acquisition on grammatical sensitivity: Evidence from on-line and off-line tasks. Applied Psycholinguistics, 16(1), 1-23. https://doi.org/10.1017/S0142716400006391

Estes, K.G., Evans, J.L., \& Else-Quest, N.M. (2007). Differences in the nonword repetition performance of children with and without specific language impairment: A meta-analysis. Journal of Speech, Language, and Hearing Research, 50(1), 177-195. https://doi.org/10.1044/1092-4388(2007/015)

Fernald, A. (1985). Four-month-old infants prefer to listen to motherese. Infant Behavior and Development, 8(2), 181-195. https://doi.org/10.1016/S0163-6383(85)80005-9

Fillmore, L.W. (1991). When learning a second language means losing the first. Early Childhood Research Quarterly, 6(3), 323-346. https://doi.org/10.1016/S0885$\underline{2006(05) 80059-6}$

Flege, J.E., Frieda, E.M., \& Nozawa, T. (1997). Amount of native-language (L1) use affects the pronunciation of an L2. Journal of Phonetics, 25(2), 169-186. https://doi.org/10.1006/jpho.1996.0040

Flege, J.E., Munro, M.J., \& MacKay, I.R. (1995). Factors affecting strength of perceived foreign accent in a second language. The Journal of the Acoustical Society of America, 97(5), 3125-3134. https://doi.org/10.1121/1.413041

Flege, J.E., Yeni-Komshian, G.H., \& Liu, S. (1999). Age constraints on second-language acquisition. Journal of Memory and Language, 41(1), 78-104. https://doi.org/10.1006/jmla.1999.2638

Freudenthal, D., Pine, J.M., Aguado-Orea, J., \& Gobet, F. (2007). Modeling the developmental patterning of finiteness marking in English, Dutch, German, and 
Spanish using MOSAIC. Cognitive Science, 31(2), 311-341.

https://doi.org/10.1080/15326900701221454

Fry, A.F., \& Hale, S. (2000). Relationships among processing speed, working memory, and fluid intelligence in children. Biological Psychology, 54(1-3), 1-34. https://doi.org/10.1016/S0301-0511(00)00051-X

Gallinat, E., \& Spaulding, T.J. (2014). Differences in the performance of children with specific language impairment and their typically developing peers on nonverbal cognitive tests: A meta-analysis. Journal of Speech, Language, and Hearing Research, 57(4), 1363-1382. https://doi.org/10.1044/2014_JSLHR-L-12-0363

Gathercole, S.E., \& Baddeley, A.D. (1990). Phonological memory deficits in language disordered children: Is there a causal connection? Journal of Memory and Language, 29(3), 336-360. https://doi.org/10.1016/0749-596X(90)90004-J

Gathercole, S.E., Hitch, G.J., Service, E., \& Martin, A.J. (1997). Phonological short-term memory and new word learning in children. Developmental Psychology, 33(6), 966-979. https://eric.ed.gov/?id=EJ561724

Gathercole, S.E., Willis, C.S., Baddeley, A.D., \& Emslie, H. (1994). The children's test of nonword repetition: A test of phonological working memory. Memory, 2(2), 103-127. https://doi.org/10.1080/09658219408258940

Gathercole, S.E., Willis, C.S., Emslie, H., \& Baddeley, A.D. (1992). Phonological memory and vocabulary development during the early school years: A longitudinal study. Developmental Psychology, 28(5), 887-898. https://eric.ed.gov/?id=EJ453430 
Goldowsky, B.N., \& Newport, E.L. (1993). Modeling the effects of processing limitations on the acquisition of morphology: the Less Is More hypothesis. In E. Clark (Ed.), The Proceedings of the 24th Annual Child Language Research Forum (pp. 124-138). Menlo Park, CA: CSLI Publications.

Golinkoff, R.M., \& Alioto, A. (1995). Infant-directed speech facilitates lexical learning in adults hearing Chinese: Implications for language acquisition. Journal of Child Language, 22(3), 703-726. https://doi.org/10.1017/S0305000900010011

Gopnik, A., Griffiths, T.L., \& Lucas, C.G. (2015). When younger learners can be better (or at least more open-minded) than older ones. Current Directions in Psychological Science, 24(2), 87-92. https://doi.org/10.1177/0963721414556653

Granena, G. (2013). Individual differences in sequence learning ability and second language acquisition in early childhood and adulthood. Language Learning, 63(4), 665-703. https://doi.org/10.1111/lang.12018

Griffiths, T.L., Sobel, D.M., Tenenbaum, J.B., \& Gopnik, A. (2011). Bayes and blickets: Effects of knowledge on causal induction in children and adults. Cognitive Science, 35(8), 1407-1455. https://doi.org/10.1111/j.1551-6709.2011.01203.x

Grigorenko, E.L., Sternberg, R.J., \& Ehrman, M.E. (2000). A theory- based approach to the measurement of foreign language learning ability: The Canal- F theory and test. The Modern Language Journal, 84(3), 390-405. https://doi.org/10.1111/0026-7902.00076

Grimshaw, G.M., Adelstein, A., Bryden, M.P., \& MacKinnon, G.E. (1998). Firstlanguage acquisition in adolescence: Evidence for a critical period for verbal 
language development. Brain and Language, 63(2), 237-255.

https://doi.org/10.1006/brln.1997.1943

Hakuta, K., Bialystok, E., \& Wiley, E. (2003). Critical evidence: A test of the criticalperiod hypothesis for second-language acquisition. Psychological Science, 14(1), 31-38. https://doi.org/10.1111/1467-9280.01415

Hamrick, P., Lum, J.A.G., \& Ullman, M.T. (2018). Child first language and adult second language are both tied to general-purpose learning systems. Proceedings of the National Academy of Sciences, 115(7) 1487-1492.

https://doi.org/10.1073/pnas.1713975115

Hart, B., \& Risley, T.R. (2003). The early catastrophe: The 30 million word gap by age 3. American Educator, 27(1), 4-9. https://eric.ed.gov/?id=EJ672461

Hartshorne, J.K., Tenenbaum, J.B., \& Pinker, S. (2018). A critical period for second language acquisition: evidence from 2/3 million English speakers. Cognition, 177, 263-277. https://doi.org/10.1016/j.cognition.2018.04.007

Hoff, E. (2003). The specificity of environmental influence: Socioeconomic status affects early vocabulary development via maternal speech. Child Development, 74(5), 1368-1378. https://doi.org/10.1111/1467-8624.00612

Hoff, E., \& Ribot, K.M. (2017). Language growth in English monolingual and SpanishEnglish bilingual children from 2.5 to 5 years. The Journal of Pediatrics, 190, 241-245. https://doi.org/10.1016/j.jpeds.2017.06.071

Hudson Kam, C.L., \& Chang, A. (2009). Investigating the cause of language regularization in adults: Memory constraints or learning effects? Journal of 
Experimental Psychology: Learning, Memory, and Cognition, 35(3), 815-821. http://dx.doi.org/10.1037/a0015097

Hudson Kam, C.L., \& Newport, E.L. (2005). Regularizing unpredictable variation: The roles of adult and child learners in language formation and change. Language Learning and Development, 1(2), 151-195.

https://doi.org/10.1080/15475441.2005.9684215

Hudson Kam, C.L., \& Newport, E.L. (2009). Getting it right by getting it wrong: When learners change languages. Cognitive Psychology, 59(1), 30-66. https://doi.org/10.1016/j.cogpsych.2009.01.001

Huttenlocher, J., Vasilyeva, M., Cymerman, E., \& Levine, S. (2002). Language input and child syntax. Cognitive Psychology, 45(3), 337-374. https://doi.org/10.1016/S0010-0285(02)00500-5

Jia, G., \& Aaronson, D. (2003). A longitudinal study of Chinese children and adolescents learning English in the United States. Applied Psycholinguistics, 24(1), 131-161. https://doi.org/10.1017/S0142716403000079

Kareev, Y. (1995). Through a narrow window: Working memory capacity and the detection of covariation. Cognition, 56(3), 263-269. https://doi.org/10.1016/0010$\underline{0277(95) 92814-\mathrm{G}}$

Karmiloff-Smith, A. (1992). Beyond modularity: A developmental perspective on cognitive science. Cambridge, MA: MIT Press.

Kempe, V. \& Brooks, P.J. (2001). The role of diminutives in the acquisition of Russian gender: Can elements of child-directed speech aid in learning morphology? Language Learning, 51, 221-256. https://doi.org/10.1111/1467-9922.00154 
Kempe, V. \& Brooks, P.J. (2011). Second language learning of complex inflectional systems. Language Learning, 58(4), 703-746. https://doi.org/10.1111/j.14679922.2008.00477.x

Kempe, V. \& Brooks, P.J. (2014, July). Less is not always more: Regularization hinders learning of inflectional morphology in 9-year-old children. Poster presented at the XIII International Congress for the Study of Child Language, Amsterdam, NL.

Kempe, V., Brooks, P.J. \& Gillis, S. (2005). Diminutives in child-directed speech supplement metric with distributional word segmentation cues. Psychonomic Bulletin and Review, 12, 145-151. https://doi.org/10.3758/BF03196360

Kempe, V., Brooks, P.J., Mironova, N. \& Fedorova, O. (2003). Diminutivization supports gender acquisition in Russian children. Journal of Child Language. 30, 471-485. https://doi.org/10.1017/S0305000903005580

Kersten, A.W., \& Earles, J.L. (2001). Less really is more for adults learning a miniature artificial language. Journal of Memory and Language, 44(2), 250-273. https://doi.org/10.1006/jmla.2000.2751

Kidd, E., Donnelly, S., \& Christiansen, M.H. (2018). Individual differences in language acquisition and processing. Trends in Cognitive Sciences, 22(2), 154-169. https://doi.org/10.1016/j.tics.2017.11.006

Kirby, S., Tamariz, M., Cornish, H., \& Smith, K. (2015). Compression and communication in the cultural evolution of linguistic structure. Cognition, 141, 87-102. https://doi.org/10.1016/j.cognition.2015.03.016

Klem, M., Melby-Lervåg, M., Hagtvet, B., Lyster, S.A.H., Gustafsson, J.E., \& Hulme, C. (2015). Sentence repetition is a measure of children's language skills rather than 
working memory limitations. Developmental Science, 18(1), 146-154. https://doi.org/10.1111/desc.12202

Krashen, S., Scarcella, R., \& Long, M. (1982). Child-adult differences in second language acquisition. Rowley, MA: Newbury House.

Kuhl, P.K. \& Iverson, P. (1995). Linguistic experience and the "perceptual magnet effect." In W. Strange (Ed.), Speech perception and linguistic experience: Issues in cross-language research (pp. 121-154). Timonium, MD: York Press.

Lenneberg, E.H. (1967). Biological foundations of language. New York: Wiley.

Lew-Williams, C., Pelucchi, B., \& Saffran, J.R. (2011). Isolated words enhance statistical language learning in infancy. Developmental Science, 14(6), 1323-1329. https://doi.org/10.1111/j.1467-7687.2011.01079.x

Linck, J.A., Osthus, P., Koeth, J.T., \& Bunting, M.F. (2014). Working memory and second language comprehension and production: A meta-analysis. Psychonomic Bulletin \& Review, 21(4), 861-883. https://doi.org/10.3758/s13423-013-0565-2

Linck, J.A., Hughes, M.M., Campbell, S.G., Silbert, N.H., Tare, M., Jackson, S.R., ... \& Doughty, C.J. (2013). Hi- LAB: A new measure of aptitude for high-level language proficiency. Language Learning, 63(3), 530-566. https://doi.org/10.1111/lang.12011

Lucas, C.G., Bridgers, S., Griffiths, T.L., \& Gopnik, A. (2014). When children are better (or at least more open-minded) learners than adults: Developmental differences in learning the forms of causal relationships. Cognition, 131(2), 284-299. https://doi.org/10.1016/j.cognition.2013.12.010 
Lum, J.A., Conti-Ramsden, G., Morgan, A.T., \& Ullman, M.T. (2014). Procedural learning deficits in specific language impairment (SLI): A meta-analysis of serial reaction time task performance. Cortex, 51, 1-10. https://doi.org/10.1016/j.cortex.2013.10.011

Ma, W., Golinkoff, R.M., Houston, D.M., \& Hirsh-Pasek, K. (2011). Word learning in infant-and adult-directed speech. Language Learning and Development, 7(3), 185-201. https://doi.org/10.1080/15475441.2011.579839

MacDonald, M.C. (2016). Speak, act, remember: The language-production basis of serial order and maintenance in verbal memory. Current Directions in Psychological Science, 25(1), 47-53. https://doi.org/10.1177/0963721415620776

Mayberry, R.I. (2007). When timing is everything: Age of first-language acquisition effects on second-language learning. Applied Psycholinguistics, 28(3), 537-549. https://doi.org/10.1017/S0142716407070294

Mayberry, R.I., \& Eichen, E.B. (1991). The long-lasting advantage of learning sign language in childhood: Another look at the critical period for language acquisition. Journal of Memory and Language, 30(4), 486-512. https://doi.org/10.1016/0749-596X(91)90018-F

Mayberry, R.I., \& Kluender, R. (2017). Rethinking the critical period for language: New insights into an old question from American Sign Language. Bilingualism: Language and Cognition. [advanced e-pub] https://doi.org/10.1017/S1366728917000724 
Mayberry, R.I., \& Lock, E. (2003). Age constraints on first versus second language acquisition: Evidence for linguistic plasticity and epigenesis. Brain and language, 87(3), 369-384. https://doi.org/10.1017/S1366728917000724

Mayberry, R.I., Lock, E., \& Kazmi, H. (2002). Development: Linguistic ability and early language exposure. Nature, 417(6884), 38-38. https://doi.org/10.1017/S1366728917000724

McDonough, L., Choi, S., \& Mandler, J.M. (2003). Understanding spatial relations: Flexible infants, lexical adults. Cognitive Psychology, 46(3), 229-259. https://doi.org/10.1016/S0010-0285(02)00514-5

Melby-Lervåg, M., Lervåg, A., Lyster, S.A.H., Klem, M., Hagtvet, B., \& Hulme, C. (2012). Nonword-repetition ability does not appear to be a causal influence on children's vocabulary development. Psychological Science, 23(10), 1092-1098. https://doi.org/10.1177/0956797612443833

Mintz, T.H. (2003). Frequent frames as a cue for grammatical categories in child directed speech. Cognition, 90, 91-117. https://doi.org/10.1016/S0010-0277(03)00140-9

Miyake, A. \& Friedman, N.P. (1998). Individual differences in second language proficiency: Working memory as language aptitude. In A.F. Healy \& L.E. Bourne Jr. (Eds.), Foreign language learning: Psycholinguistic studies on training and retention (pp. 339-364). Mahwah, NJ: Erlbaum.

Newman, A.J., Bavelier, D., Corina, D., Jezzard, P., \& Neville, H.J. (2002). A critical period for right hemisphere recruitment in American Sign Language processing. Nature Neuroscience, 5(1), 76-80. https://doi.org/10.1038/nn775 
Newport, E.L. (1988). Constraints on learning and their role in language acquisition: Studies of the acquisition of American Sign Language. Language Sciences, 10(1), 147-172. https://doi.org/10.1016/0388-0001(88)90010-1

Newport, E.L. (1990). Maturational constraints on language learning. Cognitive Science, 14, 11-28. https://doi.org/10.1207/s15516709 $\operatorname{cog} 1401 \_2$

Ninio, A. (2006). Language and the learning curve: A new theory of syntactic development. New York: Oxford University Press.

Ninio, A. (2016). Learning transitive verbs from single-word verbs in the input by young children acquiring English. Journal of Child Language, 43(5), 1103-1130. https://doi.org/10.1017/S030500091500046X

Pakulak, E., \& Neville, H.J. (2011). Maturational constraints on the recruitment of early processes for syntactic processing. Journal of Cognitive Neuroscience, 23(10), 2752-2765. https://doi.org/10.1162/jocn.2010.21586

Pan, B.A., Rowe, M.L., Singer, J.D., \& Snow, C.E. (2005). Maternal correlates of growth in toddler vocabulary production in low- income families. Child Development, 76(4), 763-782. https://doi.org/10.1111/1467-8624.00498-i1

Papagno, C., Valentine, T., \& Baddeley, A. (1991). Phonological short-term memory and foreign-language vocabulary learning. Journal of Memory and Language, 30(3), 331-347. https://doi.org/10.1016/0749-596X(91)90040-Q

Patkowski, M.S. (1990). Age and accent in a second language: A reply to James Emil Flege. Applied Linguistics, 11(1), 73-89. https://doi.org/10.1093/applin/11.1.73

Perfors, A. (2012a). Probability matching vs. over-regularization in language: Participant behavior depends on their interpretation of the task. In N. Miyake, D. Peebles, \& 
R. Cooper (Eds.), Proceedings of the 34th Annual Conference of the Cognitive Science Society (pp. 845-850). Austin, TX: Cognitive Science Society. http://mindmodeling.org/cogsci2012/papers/0155/index.html

Perfors, A. (2012b). When do memory limitations lead to regularization? An experimental and computational investigation. Journal of Memory and Language, 67(4), 486-506. https://doi.org/10.1016/j.jml.2012.07.009

Perfors, A. (2016). Adult regularization of inconsistent input depends on pragmatic factors. Language Learning and Development, 12(2), 138-155. https://doi.org/10.1080/15475441.2015.1052449

Raikes, H., Pan, B.A., Luze, G., Tamis-LeMonda, C.S., Brooks-Gunn, J., Constantine, J., ... \& Rodriguez, E.T. (2006). Mother-child bookreading in low-income families: Correlates and outcomes during the first three years of life. Child Development, 77(4), 924-953. https://doi.org/10.1111/j.1467-8624.2006.00911.x

Redington, M., Chater, N. \& Finch, S. (1998). Distributional Information: A powerful cue for acquiring syntactic structures. Cognitive Science, 22, 425-469. https://doi.org/10.1207/s15516709cog2204_2

Ribot, K.M., Hoff, E., \& Burridge, A. (2018). Language use contributes to expressive language growth: evidence from bilingual children. Child Development, 89(3), 929-940. https://doi.org/10.1111/cdev.12770

Robbins, A.M., Koch, D.B., Osberger, M.J., Zimmerman-Phillips, S., \& Kishon-Rabin, L. (2004). Effect of age at cochlear implantation on auditory skill development in infants and toddlers. Archives of Otolaryngology-Head \& Neck Surgery, 130(5), 570-574. https://doi.org/10.1001/archotol.130.5.570 
Rohde, D.L., \& Plaut, D.C. (1999). Language acquisition in the absence of explicit negative evidence: How important is starting small? Cognition, 72(1), 67-109. https://doi.org/10.1016/S0010-0277(99)00031-1

Rohde, D.L.T. \& Plaut, D.C. (2003). Less is less in language acquisition. In P. Quinlan (Ed.), Connectionist modelling of cognitive development (pp. 189-231). Hove, UK: Psychology Press.

Rowe, M.L. (2012). A longitudinal investigation of the role of quantity and quality of child- directed speech in vocabulary development. Child Development, 83(5), 1762-1774. https://doi.org/10.1111/j.1467-8624.2012.01805.x

Saffran, J.R. (2001). The use of predictive dependencies in language learning. Journal of Memory and Language, 44(4), 493-515. https://doi.org/10.1006/jmla.2000.2759

Savickienė, I., Kempe, V., \& Brooks, P.J. (2009). Acquisition of gender agreement in Lithuanian: Exploring the effect of diminutive usage in an elicited production task. Journal of Child Language, 36(3), 477-494. https://doi.org/10.1017/S0305000908009100

Schmid, M.S. (2007) The role of LI use for LI attrition. In B. Köpke (Ed.), Language attrition: Theoretical Perspectives (pp. 135-154). Amsterdam: John Benjamins.

Senghas, A., \& Coppola, M. (2001). Children creating language: How Nicaraguan Sign Language acquired a spatial grammar. Psychological Science, 12(4), 323-328. https://doi.org/10.1111/1467-9280.00359

Senghas, A., Kita, S., \& Özyürek, A. (2004). Children creating core properties of language: Evidence from an emerging sign language in 
Nicaragua. Science, 305(5691), 1779-1782.

https://doi.org/10.1126/science.1100199

Service, E. (1992). Phonology, working memory, and foreign-language learning. The Quarterly Journal of Experimental Psychology, 45(1), 21-50. https://doi.org/10.1080/14640749208401314

Ševa, N., Kempe, V., Brooks, P.J., Mironova, N., Pershukova, A., \& Fedorova, O. (2007). Crosslinguistic evidence for the diminutive advantage: gender agreement in Russian and Serbian children. Journal of Child Language, 34(1), 111-131. https://doi.org/10.1017/S0305000906007720

Snow, C.E., \& Hoefnagel-Höhle, M. (1978). The critical period for language acquisition: Evidence from second language learning. Child Development, 49(4), 1114-1128. https://doi.org/10.2307/1128751

Soderstrom, M. (2007). Beyond babytalk: Re-evaluating the nature and content of speech input to preverbal infants. Developmental Review, 27(4), 501-532. https://doi.org/10.1016/j.dr.2007.06.002

Speciale, G., Ellis, N.C., \& Bywater, T. (2004). Phonological sequence learning and short-term store capacity determine second language vocabulary acquisition. Applied Psycholinguistics, 25(2), 293-321. https://doi.org/10.1017/S0142716404001146

Stanovich, K.E. (1986). Matthew effects in reading: Some consequences of individual differences in the acquisition of literacy. Reading Research Quarterly, 21(4), 360407. https://doi.org/10.1177/0022057409189001-204 
Street, J.A., \& Dąbrowska, E. (2010). More individual differences in language attainment: How much do adult native speakers of English know about passives and quantifiers? Lingua, 120(8), 2080-2094. https://doi.org/10.1016/j.lingua.2010.01.004

Tamis-LeMonda, C.S., Bornstein, M.H., \& Baumwell, L. (2001). Maternal responsiveness and children's achievement of language milestones. Child Development, 72(3), 748-767. https://doi.org/10.1111/1467-8624.00313

Thompson-Schill, S.L., Ramscar, M., \& Chrysikou, E.G. (2009). Cognition without control: When a little frontal lobe goes a long way. Current Directions in Psychological Science, 18(5), 259-263. https://doi.org/10.1111/j.1467$\underline{8721.2009 .01648 . \mathrm{X}}$

Turkewitz, G., \& Kenny, P.A. (1982). Limitations on input as a basis for neural organization and perceptual development: A preliminary theoretical statement. Developmental Psychobiology, 15(4), 357-368. https://doi.org/10.1002/dev.420150408

Ullman, M.T. (2001). The neural basis of lexicon and grammar in first and second language: The declarative/procedural model. Bilingualism: Language and Cognition, 4(2), 105-122. https://doi.org/10.1017/S1366728901000220

Vanhove, J. (2013). The critical period hypothesis in second language acquisition: A statistical critique and a reanalysis. PLoS ONE, 8(7), e69172. http://dx.doi.org/10.1371/journal.pone.0069172.s003

Vugs, B., Cuperus, J., Hendriks, M., \& Verhoeven, L. (2013). Visuospatial working memory in specific language impairment: A meta-analysis. Research in 
Developmental Disabilities, 34(9), 2586-2597.

https://doi.org/10.1016/j.ridd.2013.05.014

Weber-Fox, C.M., \& Neville, H.J. (1996). Maturational constraints on functional specializations for language processing: ERP and behavioral evidence in bilingual speakers. Journal of Cognitive Neuroscience, 8(3), 231-256.

https://doi.org/10.1162/jocn.1996.8.3.231

Weigel, D.J., Martin, S.S., \& Bennett, K.K. (2006). Contributions of the home literacy environment to preschool-aged children's emerging literacy and language skills. Early Child Development and Care, 176(3-4), 357-378. https://doi.org/10.1080/03004430500063747

Werker, J.F., Pegg, J.E., \& McLeod, P.J. (1994). A cross-language investigation of infant preference for infant-directed communication. Infant Behavior and Development, 17(3), 323-333. https://doi.org/10.1016/0163-6383(94)90012-4

Zhu, F.F., Yeung, A. Y., Poolton, J.M., Lee, T.M., Leung, G.K., \& Masters, R.S. (2015). Cathodal transcranial direct current stimulation over left dorsolateral prefrontal cortex area promotes implicit motor learning in a golf putting task. Brain Stimulation, 8(4), 784-786. https://doi.org/10.1016/j.brs.2015.02.005

Zwart, F.S., Vissers, C.T.W., Kessels, R.P., \& Maes, J.H. (2017). Procedural learning across the lifespan: A systematic review with implications for atypical development. Journal of Neuropsychology. [advanced e-pub] https://doi.org/10.1111/jnp.12139 